ORIGINAL

\title{
Contributions of Anthropometrics and Lifestyle to Blood Pressure in Japanese University Students : Investigation by Annual Health Screening
}

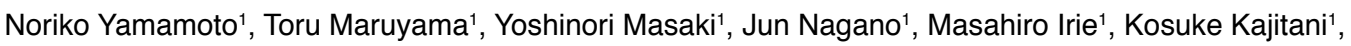
Rikako Tsuchimoto', and Takeshi Sato ${ }^{1}$

${ }^{1}$ Center for Health Sciences and Counseling, Kyushu University, Fukuoka, Japan

\begin{abstract}
Background : High blood pressure (BP) is a healthcare problem in young persons. There are racial differences in anthropometrics, dietary habit and lifestyle relating to BP. Therefore, this study investigated the relationship between anthropometrics, lifestyle and BP obtained in the Japanese university students. Materials and Methods : Participants were recruited in annual health screening including questionnaire, measurements of $\mathrm{BP}$ and anthropometrics calculating body mass index (BMI). Totally, 14,280 students (10,273 males and 4,007 females) were eligible. Multiple regression analyses were applied to predict contributors to high BP. Results : BMI was the most powerful contributor to high BP in many subgroups divided by gender and graduation $(p<0.001)$. In lifestyle, contribution of lack of exercise to high BPs was observed in the undergraduates. Smoking, drinking and breakfast skipping had no significant impact on high BP. However, smoking and drinking permeated and exercise habit declined after graduation. Prevalence of obesity (BMI $\left.\geq 25 \mathrm{~kg} / \mathrm{m}^{2}\right)$ and hypertension $(\geq 140 / 90$ $\mathrm{mmHg})$ increased in subgroups with advanced age $(\mathrm{p}<0.001)$. Conclusion: BMI was found to be the most powerful contributor to high BPs. Health literacy to modify lifestyle is important to prevent hypertension for university students who are exposed to social trends of unhealthy lifestyle. J. Med. Invest. 67: 174-181, February, 2020
\end{abstract}

Keywords : blood pressure, body mass index, healthcare, lifestyle, university students

\section{INTRODUCTION}

Hypertension is the most prevalent risk factor of cardiovascular diseases. Current guideline published by The Japanese Society of Hypertension (JSH2019) emphasizes an importance of lifestyle modification including physical activity, food education and weight control (1). There are many factors accelerating hypertension such as obesity, salty food and social environment inducing emotional stress and short sleeping time. All these sociodemographic problems are important in the university students. Lifestyle of the university students becomes unhealthy after the entrance into the university, and such lifestyle generally continues thereafter. Many students are living alone and away from their families after graduation of senior high school. They have to behave at their own risk in classroom, extracurricular outdoor activity and part-time job. Outside of the university campus, they have to keep moderation in drinking, smoking, eating fast food and internet utilization $(2,3)$. Therefore, comprehensive lifestyle modification should be promoted by educational health literacy performed in classroom or infirmary.

Racial difference in the prevalence of hypertension has been reported so far $(4,5)$, and JSH defines the normal blood pressure (BP) as systolic BP (SBP) $<120 \mathrm{mmHg}$ and diastolic BP (DBP) $<80 \mathrm{mmHg}$. It has been reported that exceeding these ranges increases the risk of hypertensive complications (1). Therefore, it is important to clarify the prevalence and causal factors of juvenile hypertension in Japanese youth. Annual health screening is mandatory in Japan by the Japanese School Health and Safety

Received for publication November 19, 2019 ; accepted February 5 , 2020.

Address correspondence and reprint requests to Toru Maruyama, MD., PhD., Center for Health Sciences and Counseling, Ito Campus, Kyushu University, Motooka 744, Nishi-ku, Fukuoka 819-0395, Japan Tel and Fax : +81-92-802-5113.
Act. Mega-data obtained by this mass screening is extremely useful for the healthcare promotion for the university students, because tracking phenomenon of high $\mathrm{BP}$ underlies transfer of juvenile into adult hypertension (6). However, there is limited data concerning nation-wide Japanese hypertensive youth. Therefore, this study investigated the relationship between the anthropometrics, lifestyle and BP obtained in an annual health screening program applied to the students of our university.

\section{METHODS}

\section{Participants}

This study was derived from the annual health screening of Kyushu University (Fukuoka, Japan) conducted on April 2015 in accordance with the Japanese School Health and Safety Act and the updated Declaration of Helsinki (2008). All procedures performed in this study were also in accordance with our institutional and/or national ethical standards. Because school-based health screening is legal annual event in all the Japanese universities, the study protocol was not argued in the institutional review board. Data extraction was informed to all the participants at the guidance of health screening and described in the self-administered questionnaire. All the students are strongly encouraged to participate the annual health screening program from the viewpoint of health maintenance, health education and health literacy. However, participants were allowed to opt out from the data extraction when they offered. Differentiation of postgraduates from graduates were performed automatically based on the self-identification cards when they underwent the health screening.

Annual health screening program includes taking histories and physical findings by physicians working at our university campus infirmary or at our university hospitals, the anthropometric measurements of body weight (BW : kg) and height 
(BH : cm), BP (mmHg) measurements, urinalysis, chest X-ray and electrocardiogram (ECG) recordings. Resting BP and pulse rate (beats per minutes : bpm) were measured semi-automatically in sitting position after taking a few minutes' rest (Kentaro HBP-9021, Omron-Colin Healthcare, Tokyo, Japan). According to JSH 2019 defining hypertension as constant office BP of $140 / 90 \mathrm{mmHg}$ or more (1), the second BP measurement was taken after 5 minutes of rest for the subjects showing the first $\mathrm{SBP} \geq 140 \mathrm{mmHg}$ and/or the first $\mathrm{DBP} \geq 90 \mathrm{mmHg}$. If the difference in $\mathrm{BP}$ was more than $10 \mathrm{mmHg}$, a third measurement was performed, and the average of the last two measurements was used for analysis. BH and BW were measured simultaneously by validated automatic device (TANITA DC-250, Tokyo, Japan), and body mass index (BMI) was calculated automatically by dividing BW (kg) by square of BH (m). By taking personal history and physical finding, apparently healthy university students were eligible in this study.

\section{Questionnaire for lifestyle}

Lifestyles and habits of the participants were evaluated by our self-administered questionnaire package designed for quality of life (QOL) assessment in the university students (7). This package consists of 66 questions to assess 5 domains of global QOL, i.e., school life (4 items), physical health (16 items), past history (26 items), family history (15 items) and desire for health consultation domains (5 items). These domain scores demonstrated good internal consistency, content validity and test-retest reliability (7). Extraction of the questionnaire items was performed as it relates to $\mathrm{BP}$ and monitored by the Cronbach's alpha coefficient of the item measure. By this analysis, five questionnaire items of exercise, drinking, smoking, breakfast taking and sleeping hours were remained. We used a frequency-quantity approach as follows ; 1 ) exercise habit (1, exercising every day ; 2 , exercising sometimes ; 3 , not exercising), 2) drinking status (1, drinking every day ; 2 , drinking socially ; 3 , not drinking), 3) smoking status (1, current smoker ; 2 , previous smoker; 3 , nonsmoker), 4) breakfast taking (1, taking every morning; 2 , taking a few days a week; 3 , skipping every morning) and 5) actual sleeping hours (hrs). These factors have been nominated in literature as health-related lifestyle components, which are related deeply not only to the physical health but also to the mental health of the university students (8-11).

\section{Statistical analysis}

Demographic variables of the enrolled participants were extracted from health screening personal cards. All continuous data were expressed as means \pm standard deviation (SD). Data sets were examined by Kolmogorov-Smirnov test and Shapiro-Wilks test for normality. Continuous data were analyzed by the unpaired Student's t test or the one-way analysis of variance (ANOVA) for normally distributed data, and by the Mann-Whitney analysis or the Kruskal-Wallis analysis for the data distributed not normally. Discrete variables were counted, expressed by percentage and analyzed by the chi-square test or the Fisher's exact test. Multiple regression analysis was performed first to predict contributors to high BP. Dependent variables were SBP and DBP, whereas independent variables were age, BMI and the components of lifestyle extracted from the questionnaire. The combination of the lifestyle components was decided by the best Cronbach's alpha. Thereafter, this analysis was applied to assess the contribution of lifestyle components to high BMI. For multivariate analyses, logarithmic transformation was performed for data which did not distributed normally. Coefficient of determination $\left(\mathrm{R}^{2}\right)$ was adjusted for the degree of freedom. None of the variables with missing data qualified. These analyses were performed using Bell Curve for Excels version 2.12 (Social Survey Research Information Co., Ltd., Tokyo, Japan). Differences with two-sided $p<0.05$ were considered to be significant.

\section{RESULTS}

\section{Baseline characteristics and gender difference}

Because annual health screening conducted at the beginning of fiscal year is legal in Japan, participation in this health screening program is encouraged strongly, yielding nearly $80 \%$ of participation rate. Baseline demographics of $\mathrm{BP}(\mathrm{mmHg})$, pulse rate $(\mathrm{bpm})$, BMI $\left(\mathrm{kg} / \mathrm{m}^{2}\right)$ and lifestyle in all the participants $(\mathrm{n}=14,280)$ are detailed in Table 1 . All the continuous data listed in Table 1 did not show normality at all. Mean age in all males did not differ from that in all females $(p=0.113)$. Gender difference was found in SBP, DBP and pulse rate in undergraduate $(p<0.001)$ and graduate $(p<0.001)$ students. SBP and DBP were significantly $(p<0.001)$ higher in the male students compared to the female counterparts, whereas pulse rate in the male students was less than that in the female students $(p<0.001)$. Small but significant $(p<0.001)$ gender difference was found in BMI which was greater in males relative to females in both graduates and undergraduates. These data indicate that Japanese youth are generally resistant to the social and environmental factors leading to the obesity as in literature (12).

\section{Correlations of lifestyle, age and gender}

With respect to the lifestyle components, smoking, drinking, exercise habit, breakfast taking and sleeping hours were skimmed from questionnaire due to the best Cronbach's alpha (0.43). The percentage of graduate smokers was greater than that of undergraduate smokers in both males and females $(p<$ 0.001 ), and percentage of male smokers was greater than that in the female smokers both in graduates and undergraduates $(\mathrm{p}$ $<0.001)$. The same was true in the percentage of drinking, i.e., percentages of daily and social drinkers in the graduates were greater than those in the undergraduates in males $(p<0.001)$ and females $(p<0.001)$, and the percentage of male drinkers was greater than that of female drinkers in both graduates $(\mathrm{p}<$ $0.001)$ and undergraduates ( $p<0.001)$. Smoking and drinking in teenagers are illegal in Japan, and the percentages of smoking and drinking in teenager male students were less than $1.1 \%$ and $1.2 \%$, respectively.

With regards to exercise, male students were more likely $(\mathrm{p}<$ $0.001)$ to be engaged in exercise compared to the female counterparts, although such exercise habit in the male graduates was less than that in the male undergraduates $(p<0.001)$. With respect to breakfast, gender difference was found in the prevalence of breakfast skippers, i.e., breakfast skipping in females (59\%) was significantly $(p<0.001)$ prevalent as compared with that in males (47\%). Constant breakfast skippers were found in more than half of the male (55\%) and female (65\%) undergraduates. This trend was improved in the graduate students, although more than half of the female graduates were the constant breakfast skippers (52\%). Therefore, just half (50\%) of all the participants were found to be constant breakfast skippers. Finally, sleeping hours showed no gender difference and no difference between the graduate and undergraduate students (Table 1).

\section{Correlations of BMI, BPs and age}

In order to investigate the age-dependence of BP and BMI, all male participants were divided by age into the four groups of $\mathrm{A}$ (age $<20$ yo), B $(20$ yo $\leq$ age $<25$ yo), $\mathrm{C}(25$ yo $\leq$ age $<30$ yo) and $\mathrm{D}(30$ yo $\leq$ age). Likewise, all female subjects were divided in the four groups by this criterion. The mode, median and mean 
Table 1. Blood pressures, pulse rate and life style in our university students

\begin{tabular}{lcccc}
\hline & Male undergraduates & Male graduates & Female undergraduates & Female graduates \\
\hline $\mathrm{n}$ & 6405 & 3868 & 2680 & 1327 \\
\hline Age (years)§ & $20 \pm 2.0$ & $25 \pm 4.0$ & $20 \pm 1.6$ & $26 \pm 4.8$ \\
SBP (mmHg)\# & $126 \pm 14$ & $127 \pm 15$ & $112 \pm 13$ & $112 \pm 12$ \\
\hline DBP (mmHg)* & $71 \pm 10$ & $74 \pm 11$ & $66 \pm 9$ & $67 \pm 9$ \\
Pulse rate (bpm)* & $79 \pm 15$ & $78 \pm 14$ & $82 \pm 14$ & $80 \pm 13$ \\
\hline BMI (kg/m²* & $21.4 \pm 2.8$ & $22.2 \pm 3.3$ & $20.6 \pm 2.4$ & $20.8 \pm 2.8$ \\
Smoking (\%)* & $389 / 134 / 5832$ & $523 / 242 / 2853$ & $26 / 14 / 2621$ & $29 / 29 / 1126$ \\
$\quad($ current/previous / no) & $(6 / 2 / 92)$ & $(14 / 7 / 79)$ & $(1 / 1 / 98)$ & $(2 / 2 / 96)$ \\
Drinking (\%)* & $72 / 1259 / 5027$ & $132 / 1163 / 2338$ & $13 / 380 / 2273$ & $23 / 235 / 926$ \\
$\quad($ daily / social / no) & $(1 / 20 / 79)$ & $(4 / 32 / 64)$ & $(1 / 14 / 85)$ & $(2 / 20 / 78)$ \\
Exercise (\%)* & $903 / 3476 / 1966$ & $236 / 1956 / 1422$ & $146 / 1088 / 1429$ & $57 / 507 / 617$ \\
$\quad$ (daily / casual / no) & $(14 / 55 / 31)$ & $(7 / 54 / 39)$ & $(5 / 41 / 54)$ & $(5 / 43 / 52)$ \\
Taking breakfast (\%)* & $783 / 2090 / 3480$ & $795 / 1465 / 1366$ & $164 / 761 / 1738$ & $144 / 420 / 619$ \\
$\quad$ (daily / sometimes / no) & $(12 / 33 / 55)$ & $(22 / 40 / 38)$ & $(6 / 29 / 65)$ & $(12 / 36 / 52)$ \\
Sleeping hours (hrs) & $6.0 \pm 1.0$ & $6.0 \pm 1.0$ & $6.0 \pm 0.9$ & $6.0 \pm 1.0$ \\
\hline
\end{tabular}

Symbols indicate significant $(\mathrm{p}<0.001)$ difference in every paired comparison among the four groups $(*)$, that in the limited paired comparison among the male and female students (\#) and that in the limited paired comparison among the graduate and undergraduate students (\$).

BMI : body mass index $\left(\mathrm{kg} / \mathrm{m}^{2}\right)$, DBP : diastolic blood pressure, SBP : systolic blood pressure.

of male BMI $\left(\mathrm{kg} / \mathrm{m}^{2}\right)$ in group A were $21.0,20.8,21.2 \mathrm{~kg} / \mathrm{m}^{2}$, respectively. These respective values in group B were $21.3,21.2$, $21.6 \mathrm{~kg} / \mathrm{m}^{2}$. These three values of group $\mathrm{C}$ were $21.6,22.5,23.0$ $\mathrm{kg} / \mathrm{m}^{2}$, and these in group D were $22.4,23.4,24.2 \mathrm{~kg} / \mathrm{m}^{2}, \mathrm{re}-$ spectively (Figure 1). Similarly, these three values of female BMI were $20.1,20.3,20.5 \mathrm{~kg} / \mathrm{m}^{2}$ in group A, 20.3, 20.4, $20.6 \mathrm{~kg} / \mathrm{m}^{2}$ in group $\mathrm{B}, 19.9,20.5,20.9 \mathrm{~kg} / \mathrm{m}^{2}$ in group $\mathrm{C}$ and $19.6,20.9$, $21.9 \mathrm{~kg} / \mathrm{m}^{2}$ in group D (Figure 2). The mode of BMI increased gradually and significantly $(\mathrm{p}<0.001)$ as age increases in males, whereas this mode remained in about $20 \mathrm{~kg} / \mathrm{m}^{2}$ in females irrespective of age.

With respect to BPs (SBP and DBP), the mode, median and mean of male BP in group A were 123/69, 125/70 and 126/70 $\mathrm{mmHg}$, respectively. These values in group B were $123 / 71$, $126 / 71,127 / 72 \mathrm{mmHg}$, these values in group $\mathrm{C}$ were $119 / 78$, $126 / 75,128 / 75 \mathrm{mmHg}$, and these in group D were $121 / 78$, $128 / 77$ and $129 / 78 \mathrm{mmHg}$, respectively. Similarly, the paired female BPs were 105/66, 112/66, 113/66 mmHg in group A, $109 / 62,111 / 66,112 / 66 \mathrm{mmHg}$ in group B, 114/71, 112/67, $112 / 67 \mathrm{mmHg}$ in group $\mathrm{C}$ and $104 / 67,113 / 68,115 / 70 \mathrm{mmHg}$ in group $\mathrm{D}$, respectively. Small but significant $(\mathrm{p}<0.001)$ rise in paired BPs was observed in male but not in female students. Cut-off BPs for screening hypertension are $140 \mathrm{mmHg}$ for $\mathrm{SBP}$ and/or $90 \mathrm{mmHg}$ for DBP. Elevated BP was defined as $\mathrm{SBP}=130-139 \mathrm{mmHg}$ and $/$ or $\mathrm{DBP}=80-89 \mathrm{mmHg}$, and high normal $\mathrm{BP}$ as $\mathrm{SBP}=120-129 \mathrm{mmHg}$ and $/$ or $\mathrm{DBP}<80 \mathrm{mmHg}$ according to the Guideline of JSH 2019 (1). The prevalence of hypertension as related to the different age groups was shown in Figure 3. Totally, it was $17.3 \%$ in males and $2.3 \%$ in females. However, the prevalence of elevated BP was $21.1 \%$ in males and $6.5 \%$ in females, and that of high normal BP was $29.9 \%$ in males and $16.2 \%$ in females.

Obesity is defined as BMI $\geq 25.0 \mathrm{~kg} / \mathrm{m}^{2}$ according to the criteria of the Japan Society for the Study of Obesity (13), because the prevalence of obesity-related complications increases rapidly in subjects showing $\mathrm{BMI} \geq 25.0 \mathrm{~kg} / \mathrm{m}^{2}$ (14). The prevalence of obesity among the four age groups was also shown in Figure 3. As in literature reporting gender difference in cardiovascular

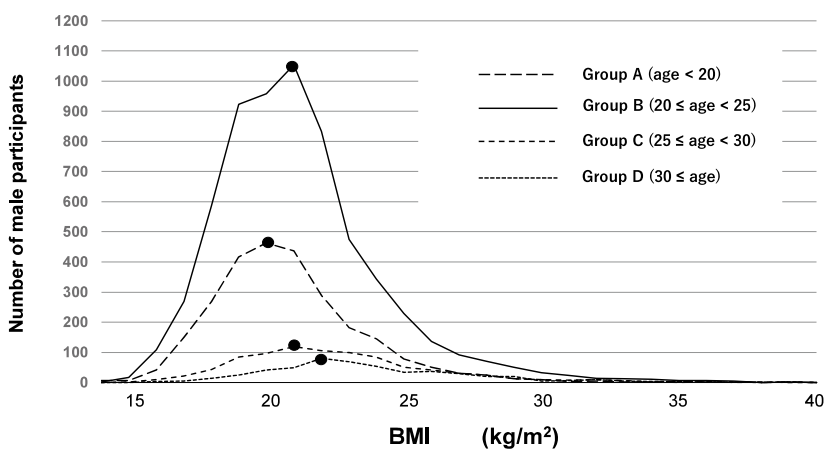

Figure 1. Histogram images of BMI $\left(\mathrm{kg} / \mathrm{m}^{2}\right)$ distribution demonstrated by dividing male participants by age (years old ; y.o.) into the four groups of A (age < 20 y.o.), B (20 y.o. $\leq$ age < 25 y.o.), C $(25$ y.o. $\leq$ age $<30$ y.o.) and D (30 y.o. $\leq$ age). Points on the distribution curves indicate mode, which increased significantly $(p<0.001)$ according to aging.

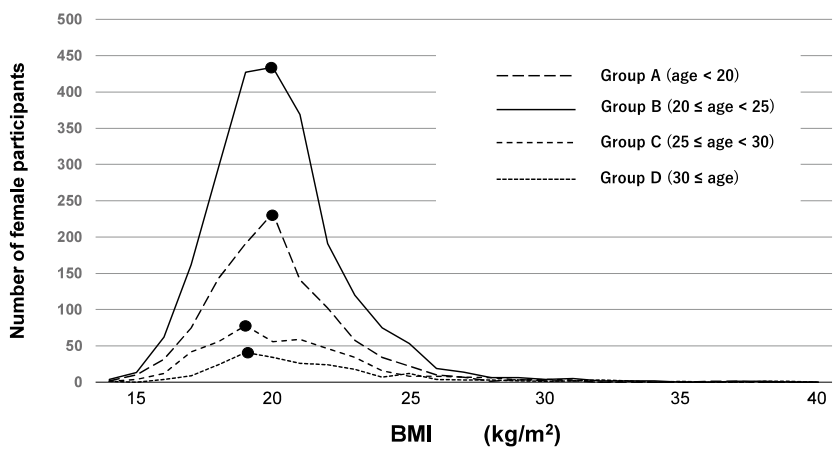

Figure 2. Histogram images of BMI $\left(\mathrm{kg} / \mathrm{m}^{2}\right)$ distribution demonstrated by dividing female participants by age into the four groups as shown in Figure 1. Points on the distribution curves indicate mode, which remains in about $20 \mathrm{~kg} / \mathrm{m}^{2}$ irrespective of aging. 


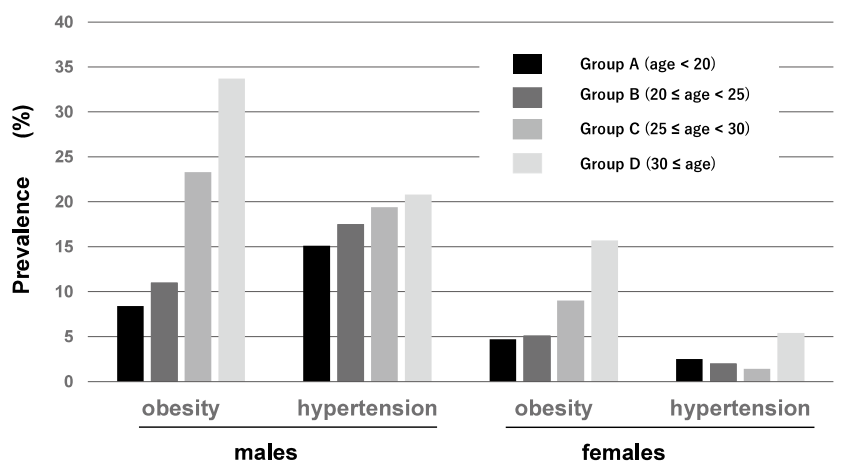

Figure 3. Prevalence of obesity and hypertension in different four age groups. Marked increase in the prevalence of obesity as increasing age was observed in both males and females $(p<0.001)$, whereas steady increase in the prevalence of hypertension was noted not in the females but in the males $(p<0.001)$. risk accumulation (15), the prevalence of obesity and hypertension was evident in males relative to females. Moreover, marked increase in the prevalence of obesity as increasing age was observed in both males and females $(p<0.001)$, whereas steady increase in the prevalence of hypertension was noted in males $(p<0.001)$ but not in females.

\section{Correlations of BMI, BPs and lifestyle}

Lifestyle is deeply related to the BPs in the university students' reports $(9,10,11,16)$. In the multivariate analyses, BMI, age and lack of exercise were the variables significantly $(\mathrm{p}<$ 0.001) contributing to high BPs in the male undergraduates (Table 2). On the other hand, both BMI and lack of exercise had significantly $(\mathrm{p}<0.001)$ positive impact on high BPs in the female undergraduates (Table 3). In the male graduate students, BMI was the most significant $(p<0.001)$ contributor to high BPs (Table 4). In the female graduates, BMI and age were the significant $(p<0.001)$ contributors to high BPs (Table 5). As a

Table 2. Determinants of blood pressures in the male undergraduates

\begin{tabular}{lcccc}
\hline SBP & $\beta(95 \% \mathrm{CI})$ & standardized $\beta$ & partial $\mathrm{r}$ & $\mathrm{p}$ value \\
\hline BMI & $1.5666(1.4464-1.6868)$ & 0.3091 & 0.3059 & $\mathrm{P}<0.001$ \\
Exercise & $1.2134(0.6981-1.7286)$ & 0.0553 & 0.0580 & $\mathrm{P}<0.001$ \\
Age & $0.3264(0.1465-0.5064)$ & 0.0451 & 0.0447 & $\mathrm{P}<0.001$ \\
\hline Drinking & $0.8918(0.0774-1.7062)$ & 0.0276 & 0.0270 & 0.0319 \\
Smoking & $0.5159(-0.1901-1.2219)$ & 0.0179 & 0.0180 & 0.1520 \\
Sleeping hours & $0.2410(-0.1185-0.6005)$ & 0.0157 & 0.0165 & 0.1888 \\
\hline & & & $\left(\mathrm{R}^{2}=0.1002, \mathrm{~F}=117.3460, \mathrm{P}<0.001\right)$ \\
\hline DBP & $\beta(95 \% \mathrm{CI})$ & $\mathrm{partial} \mathrm{r}$ & $\mathrm{p}$ value \\
\hline BMI & $0.6248(0.5350-0.7145)$ & 0.1697 & 0.1691 & $\mathrm{P}<0.001$ \\
Age & $0.5745(0.4401-0.7089)$ & 0.1093 & 0.1048 & $\mathrm{P}<0.001$ \\
Exercise & $1.5466(1.1588-1.9345)$ & 0.0971 & 0.0978 & $\mathrm{P}<0.001$ \\
Drinking & $0.6418(0.0439-1.2397)$ & 0.0273 & 0.0265 & 0.0354 \\
Sleeping hours & $0.3032(0.0351-0.5713)$ & 0.0272 & 0.0279 & 0.0267 \\
Taking breakfast & $0.2808(-0.0893-0.6509)$ & 0.0190 & 0.0187 & 0.1369 \\
\hline & & & $\left(\mathrm{R}^{2}=0.0526, \mathrm{~F}=58.4930, \mathrm{P}<0.001\right)$
\end{tabular}

$\beta$ : partial regression coefficient, CI: confidence interval, $r$ : correlation coefficient.

$\left.\mathrm{R}^{2}=0.0526, \mathrm{~F}=58.4930, \mathrm{P}<0.001\right)$

Table 3. Determinants of blood pressures in the female undergraduates

\begin{tabular}{lcccc}
\hline SBP & $\beta(95 \% \mathrm{CI})$ & standardized $\beta$ & partial $\mathrm{r}$ & $\mathrm{p}$ value \\
\hline BMI & $1.3406(1.1518-1.5294)$ & 0.2612 & 0.2612 & $\mathrm{P}<0.001$ \\
Drinking & $2.6187(1.3822-3.8552)$ & 0.0777 & 0.0804 & $\mathrm{P}<0.001$ \\
Exercise & $1.4526(0.6805-2.2246)$ & 0.0693 & 0.0715 & $\mathrm{P}<0.001$ \\
Sleeping hours & $0.6019(0.0973-1.1065)$ & 0.0437 & 0.0454 & 0.0194 \\
\hline \multicolumn{1}{c}{} & & $\left(\mathrm{R}^{2}=0.0769, \mathrm{~F}=55.1615, \mathrm{P}<0.001\right)$ \\
\hline DBP & $\beta(95 \% \mathrm{CI})$ & standardized $\beta$ & partial $\mathrm{r}$ & $\mathrm{p}$ value \\
\hline BMI & $0.5287(0.3885-0.6689)$ & 0.1425 & 0.1422 & $\mathrm{P}<0.001$ \\
Exercise & $1.1165(0.5444-1.6887)$ & 0.0737 & 0.0741 & $\mathrm{P}<0.001$ \\
Sleeping hours & $0.3690(-0.0058-0.7437)$ & 0.0371 & 0.0375 & 0.0536 \\
\hline
\end{tabular}

Abbreviations are as follows in Tables 1 and 2 . 
Table 4. Determinants of blood pressures in the male graduates

\begin{tabular}{|c|c|c|c|c|}
\hline $\mathrm{SBP}$ & $\beta(95 \% \mathrm{CI})$ & standardized $\beta$ & partial r & $\mathrm{p}$ value \\
\hline BMI & $1.6021(1.4623-1.7419)$ & 0.3525 & 0.3515 & $\mathrm{P}<0.001$ \\
\hline Sleeping hours & $0.5552(0.1022-1.0082)$ & 0.0377 & 0.0401 & 0.0163 \\
\hline \multirow[t]{2}{*}{ Taking breakfast } & $-0.6674(-1.2719--0.0628)$ & -0.0339 & -0.0361 & 0.0305 \\
\hline & & & \multicolumn{2}{|c|}{$\left(\mathrm{R}^{2}=0.1261, \mathrm{~F}=172.3482, \mathrm{P}<0.001\right)$} \\
\hline DBP & $\beta(95 \% \mathrm{CI})$ & standardized $\beta$ & partial $r$ & $\mathrm{p}$ value \\
\hline BMI & $0.8898(0.7876-0.9919)$ & 0.2749 & 0.2744 & $\mathrm{P}<0.001$ \\
\hline Age & $0.4016(0.3129-0.4903)$ & 0.1454 & 0.1468 & $\mathrm{P}<0.001$ \\
\hline Taking breakfast & $0.4783(0.0331-0.9235)$ & 0.0341 & 0.0352 & 0.0352 \\
\hline Smoking & $0.3926(-0.0679-0.8531)$ & 0.0268 & 0.0279 & 0.0947 \\
\hline
\end{tabular}

Abbreviations are as follows in Tables 1 and 2.

Table 5. Determinants of blood pressures in the female graduates

\begin{tabular}{|c|c|c|c|c|}
\hline $\mathrm{SBP}$ & $\beta(95 \% \mathrm{CI})$ & standardized $\beta$ & partial $r$ & $\mathrm{p}$ value \\
\hline BMI & $1.3567(1.1211-1.5924)$ & 0.3113 & 0.3130 & $\mathrm{P}<0.001$ \\
\hline Age & $0.2784(0.1389-0.4179)$ & 0.1079 & 0.1135 & $\mathrm{P}<0.001$ \\
\hline & & & \multicolumn{2}{|c|}{$\left(\mathrm{R}^{2}=0.1143, \mathrm{~F}=75.8403, \mathrm{P}<0.001\right)$} \\
\hline $\mathrm{DBP}$ & $\beta(95 \% \mathrm{CI})$ & standardized $\beta$ & partial $r$ & $\mathrm{p}$ value \\
\hline BMI & $0.7391(0.5559-0.9224)$ & 0.2216 & 0.2250 & $\mathrm{P}<0.001$ \\
\hline Age & $0.3452(0.2368-0.4537)$ & 0.1748 & 0.1792 & $\mathrm{P}<0.001$ \\
\hline
\end{tabular}

Abbreviations are as follows in Tables 1 and 2.

$\left(\mathrm{R}^{2}=0.0863, \mathrm{~F}=55.5044, \mathrm{P}<0.001\right)$

whole, BMI showed the greatest standardized partial regression coefficient $(\beta)$ in each regression model, indicating the most powerful impact on high BPs.

Multiple regression analysis was applied to the BMI as a dependent variable and lifestyle components as independent variables, because BMI was the most powerful contributor to high BPs. In the undergraduates, all the unhealthy life style components (drinking, smoking, lack of exercise, skipping breakfast, shortage of sleeping time) were significantly proportional to BMI in males, but lack of exercise alone was a contributor to high BMI in females. In the graduates, smoking, short sleeping hour and skipping breakfast were the contributors to high BMI in males, whereas significant multiple regression model was not obtained in females. Generally, males appeared sensitive to various unhealthy life style components increasing BW relative to females (not shown).

\section{DISCUSSION}

In this cross-sectional survey of the Japanese students in our university, the prevalence of obesity and hypertension increased with age, because BMI was the most powerful contributor to high BPs irrespective of gender and graduation. In the questionnaire of this study, their general lifestyle was not necessarily healthy in that 1) a steady part of students started smoking and drinking after graduation, 2) more than half of female students showed lack of exercise, and male students tended to cease exercise after graduation, and 3) just half of the participants $(50 \%)$ were the constant breakfast skippers. These indicate that lifestyle modification should be promoted to prevent future development of the BMI-dependent hypertension by educational health literacy (17).

Legal annual health screening conducted in every school of Japan has healthcare benefit. This is particularly important for university students being in a transitional stage of life, getting unhealthy habits through the lifespan leading to substantial anthropometric changes in this life stage. Anthropometrics are important health and fitness indicators. Especially, BMI has a strong impact on BPs as well as on the ECG findings $(16,18)$, i.e., consensus is acquired in many updated guidelines with respect to that systemic obesity is associated with hypertension $(1,19,20)$. Cut-off point of BMI defining obesity differs internationally. $\mathrm{BMI} \geq 25.0 \mathrm{~kg} / \mathrm{m}^{2}$ discriminating obesity by the criterion of the Japan Society for the Study of Obesity yields age-dependent increase in the prevalence of obesity as in Figure 3 (13), i.e., this criterion yields $5.0 \%$ obese female and $9.5 \%$ obese male undergraduates, whereas it yields $8.1 \%$ obese female and $17.5 \%$ obese male graduates. These results indicate that such cut-off criteria for BMI are appropriate in the university student healthcare.

Although age-dependent increase in obese university students was confirmed, Japanese adolescents have demonstrated no evidence of a major rise in the prevalence of obesity for the last half century in spite of the global trend toward an increase in adolescents BMI $(12,21)$. This trend is supported by low BMI in all the participants with mean BMI ranging from 20.6 to 22.2 $\mathrm{kg} / \mathrm{m}^{2}$ (Table 1). Moreover, the distribution of male BMI showed positive skewness of 1.18 in group A, 1.31 in group B, 1.05 in group C, 0.95 in group D (Figures 1). Likewise, the skewness 
of female BMI distribution was 1.27 in group A, 1.38 in group $\mathrm{B}, 1.08$ in group $\mathrm{C}$, and 1.73 in group $\mathrm{D}$, respectively (Figure 2). This is caused by unhealthy social trend toward inaccurate weight perception, i.e., overweight is considered as anthropometric minority in Japanese youth (22), which influences greatly the lifestyle of the university students and is a matter of health literacy for the university students (23).

Age is another important factor contributing to high BPs. In the male students, age-dependent rise in BPs was confirmed in both undergraduates and graduates (Tables 2, 4). On the other hand, this trend was confirmed in the female graduates (Table 5) but not in the female undergraduates (Table 3). This survey could not provide accurate explanation for these results. Although it is possible to hypothesize that the delayed effects of aging on an elevation of BPs in females is related to the estrogen, large cohort with long-term prospective study is required to test this hypothesis. Another gender difference was obtained in the habit of exercise. Exercise has a strong impact for prevention of hypertension in general population (24). Relatively, such evidence is poor in the university students. In this study, lack of exercise has significantly positive impact on high BPs in undergraduate students alone (Tables 2, 3). Generally, lifestyle becomes busier after graduation for laboratory work and writing dissertation, and graduate students have less time to take exercise. Actually, half $(53.2 \%)$ of the graduate students showed no habit of exercise in this study (Table 1). This should be followed up to examine whether lack of exercise in youth underlies future hypertension and to validate the exercise promotion in health literacy (16).

Although the other lifestyle factors of smoking, drinking and taking breakfast have limited influence on BPs in our study, the causality of these factors is a matter of future study. Just half of participants $(50 \%)$ were the constant breakfast skippers, which had no impact on BP. However, this finding does not deny the possible effects of breakfast skipping on future development of cardiovascular disease (25). It is unknown whether breakfast skipping is associated with unhealthy food and snack consumption in the participants. The main reasons for skipping breakfast are busy life and desire for weight reduction. One of the reasons for smoking is also the weight reduction, and smoking and drinking are interdependent in the university lifestyle. Since modifiable lifestyle components are clustering in adolescents, interdependency should be investigated in the longitudinal or multivariate study (26). Because obesity is associated with systemic vascular and cardiac damage (27-30), lifestyle modification is important for the unhealthy university students. One month after the primary health screening, secondary screening is performed in our infirmary for the students showing high BPs ( $\mathrm{SBP} \geq 140$ and/or $\mathrm{DBP} \geq 90 \mathrm{mmHg}$ ) constantly in the primary screening. The repetitive BPs measurement is educational to learn natural BPs fluctuation, relationship of BMI and BPs, and self-control of BMI (15).

\section{Strengths and limitations}

The strengths of this study are sufficient sample size to analyze appropriately the gender- and age-dependent prevalence of obesity, hypertension and lifestyle components under legal school-based survey of annual health screening program showing nearly $80 \%$ of participation rate. However, the findings of this study should be interpreted carefully due to some limitations. First of all, this is a cross-sectional study, and hence the comparison of graduates with undergraduates was not longitudinal. Prevalence of white-coat and masked hypertension was reported to be $7.5 \%$ and $2.2 \%$ in adolescents, respectively (31), but was not confirmed in this study without home BP monitoring. Second limitation is the unknown causality among smoking, drinking, breakfast skipping and sedentary lifestyle because of the cross-sectional screening associated with questionnaire study. Third, the relatively low coefficients of determination $\left(\mathrm{R}^{2}\right)$ ranging from 0.025 to 0.126 indicate unknown causes or confounders associated with juvenile hypertension, and $20 \%$ of non-participants may have a chance to improve $\mathrm{R}^{2}$ in multiple regression analyses. The relationship between future development of hypertension and the university lifestyle should wait for future study using large cohort with lifestyle intervention.

\section{CONCLUSIONS}

Hypertension is a major healthcare problem in the university students considering tracking phenomenon of casual high BPs leading to the future hypertension (6). Although some limitations permit, BMI was found to be the most powerful contributor to high BPs irrespective of gender and graduation in this study. Contribution of sedentary lifestyle to high BPs was observed in the undergraduates. Smoking, drinking and breakfast skipping had no major impact on high BPs in our university students. However, such unhealthy lifestyle may have long-term effects on the development of hypertension. In this sense, lifestyle counseling and health literacy focusing on weight control are required for the university students (32), who are exposed to social trends of unhealthy habits.

\section{ACKNOWLEDGEMENTS}

The authors wish to thank Ms. Yoshiko Yoshimura for secretarial assistance and all the public health nurses in the Center for Health Sciences and Counseling for assistance in the annual health screening of the Kyushu University. The authors thank also Dr. Atsushi Ichimiya (Professor Emeritus, Center for Health Sciences and Counseling, Kyushu University) for development and validity assessment of our self-administered health-supporting questionnaire package (7) and Dr. Keiko Uezono (Professor Emeritus, Institute of Health Science, Kyushu University) for her prior study which provided us motif of the present study (6).

\section{CONFLICT OF INTEREST}

The authors have no conflicts of interest to declare.

\section{FUNDING SOURCES}

This work was supported in part by academic support from TANITA Healthy Weight Community Trust (TANITA Co, Ltd., Tokyo, Japan), ASTELLAS Research Support (ASTELLAS Co, Ltd., Tokyo, Japan) and SOUSEIKAI Global Clinical Research Center (LTA Medical Corporation, Fukuoka, Japan).

\section{REFERENCES}

1. Umemura S, Arima H, Arima S, Asayama K, Dohi Y, Hirooka Y, Horio T, Hoshide S, Ikeda S, Ishimitsu T, Ito M, Ito S, Iwashima Y, Kai H, Kamide K, Kanno Y, Kashihara N, Kawano Y, Kikuchi T, Kitamura K, Kitazono T, Kohara K, Kudo M, Kumagai H, Matsumura K, Matsuura H, Miura K, Mukoyama M, Nakamura S, Ohkubo T, Ohya Y, Okura T, Rakugi H, Saitoh S, Shibata H, Shimosawa T, Suzuki 
H, Takahashi S, Tamura K, Tomiyama H, Tsuchihashi T, Ueda S, Uehara Y, Urata H, Hirawa N : The Japanese Society of Hypertension Guidelines for the Management of Hypertension (JSH 2019). Hypertens Res 42 : 1235-1481, 2019

2. Janeswar A, Kumar G, Kanungo S, Singh A, Subramanya GB, Jha K : Prevalence patterns and profile of adolescent tobacco users findings from a youth survey: A cross-sectional study. J Family Med Prim Care 8 : 2017-2022, 2019

3. Gruzieva TS, Galiienko LI, Holovanova IA, Zamkevich VB, Antonyuk OY, Konovalova LV, Dolynskyj RG, Zshyvotovska $\mathrm{AI}$ : Prevalence of bad habits among students of the institutions of higher medical education and ways of counteraction. Wiad Lek 72 : 384-390, 2019

4. Hoshide S, Cheng HM, Huang Q, Park S, Park CG, Chen $\mathrm{CH}$, Wang JG, Kario K: Characteristics On the ManagEment of Hypertension in Asia - Morning Hypertension Discussion Group (COME Asia MHDG). Role of ambulatory blood pressure monitoring for the management of hypertension in Asian populations. J Clin Hypertens 19 : 1240-1245, 2017

5. Husain A, Lin FC, Tuttle LA, Olsson E, Viera AJ : The reproducibility of racial differences in ambulatory blood pressure phenotypes and measurements. Am J Hypertens 30 : 961-967, 2017

6. Kawasaki T, Uezono K, Sanefuji M, Utsunomiya H, Fujino T, Kanaya S, Babazono A : A 17-year follow-up study of hypertensive and normotensive male university students in Japan. Hypertens Res 26 : 445-52, 2003

7. Ichimiya A, Babazono A, Minematsu O, Fukumori H, Uezono K, Maruyama T, Nagano J, Fujino T: A questionnaire designated 'the package for health support and screening' on health support for 1st-yaear students at Kyushu University and its reliability (written in Japanese with English abstract). J Health Sci 24 : 85-90, 2002

8. Lovell GP, Nash K, Sharman R, Lane BR : A cross-sectional investigation of depressive, anxiety, and stress symptoms and health-behavior participation in Australian university students. Nurs Health Sci 17 : 134-142, 2015

9. Aynaci G, Akdemir O : The Relationship between lifestyle, health promotion lifestyle profile II and high blood pressure in university students. Maced J Med Sci 6 : 1756-1761, 2018

10. Alhawari HH, Al-Shelleh S, Alhawari HH, Al-Saudi A, Al-Majali DA, Al-Faris L, AlRyalat SA : Blood pressure and its association with gender, body mass index, smoking, and family history among university students. Int J Hypertens 2018: 4186496, 2018

11. Sembiring K, Ramayani OR, Lubis M : Mean blood pressure difference among adolescents based on dyssomnia types. Maced J Med Sci 6 : 293-296, 2018

12. Hermanussen M, Molinari L, Satake T: BMI in Japanese children since 1948 : no evidence of a major rise in the prevalence of obesity in Japan. J Biol Clin Anthropol 65 : 275283,2007

13. Japan Society for the Study of Obesity : Diagnostic criteria of obesity. J Jpn Soc Study Obes 17 (Extra Edition) : 1-8, 2011

14. Examination Committee of Criteria for 'Obesity Disease' in Japan; Japan Society for the Study of Obesity : New criteria for 'obesity disease' in Japan. Circ J 66 : 987-92, 2002

15. Rimárová K, Dorko E, Diabelková J, Sulinová Z, Urdzík P, Pelechová N, Konrádyová N : Prevalence of lifestyle and cardiovascular risk factors in a group of medical students. Cent Eur J Public Health 26 (Suppl) : S12-S18, 2018

16. Kawabe H, Azegami T, Takeda A, Kanda T, Saito I, Saruta $\mathrm{T}$, Hirose $\mathrm{H}$ : Features of and preventive measures against hypertension in the young. Hypertens Res 42 : 935-948,
2019

17. Ozemek C, Phillips SA, Popovic D, Laddu-Patel D, Fancher IS, Arena R, Lavie CJ : Nonpharmacologic management of hypertension : a multidisciplinary approach. Curr Opin Cardiol 32 : 381-388, 2017

18. Maruyama T, Yamamoto N, Kajitani K, Tsuchimoto R, Masaki Y, Nagano J, Irie M, Ichimiya A, Yamamoto K, Uezono K : Correlations between anthropometrics and electrocardiographic variables in Japanese University students : investigation by annual health screening. Cardiol Angiol Int 6 : e1-e12, 2017. doi : 10.9734/CA/2017/36193.

19. Nagai M, Ohkubo T, Murakami Y, Takashima N, Kadota A, Miyagawa N, Saito Y, Nishi N, Okuda N, Kiyohara Y, Nakagawa H, Nakamura Y, Fujiyoshi A, Abbott RD, Okamura T, Okayama A, Ueshima H, Miura K; NIPPON DATA80/90/2010 Research Group : Secular trends of the impact of overweight and obesity on hypertension in Japan, 1980 - 2010. Hypertens Res 38 : 790-795, 2015

20. Whelton PK, Carey RM, Aronow WS, Casey DE Jr, Collins KJ, Dennison Himmelfarb C, DePalma SM, Gidding S, Jamerson KA, Jones DW, MacLaughlin EJ, Muntner P, Ovbiagele B, Smith SC Jr, Spencer CC, Stafford RS, Taler SJ, Thomas RJ, Williams KA Sr, Williamson JD, Wright JT : 2017 ACC/AHA/AAPA/ABC / ACPM/AGS/APhA/ ASH/ASPC/NMA/PCNA Guideline for the prevention, detection, evaluation, and management of high blood pressure in adults : A report of the American College of Cardiology/American Heart Association task force on clinical practice guidelines. J Am Coll Cardiol 71 : e127-e248, 2018 (e-pub ahead of print 15 May 2018; doi : 10.1016/j. jacc.2017.11.006.)

21. Skinner AC, Perrin EM, Moss LA, Skelton JA : Cardiometabolic risks and severity of obesity in children and young adults. N Engl J Med 373 : 1307-1317, 2015

22. Martin MA, Frisco ML, May AL: Gender and race/ethic differences in inaccurate weight perceptions among U.S. adolescents. Womens Health Issues 19 : 292-299, 2009

23. Mori N, Asakura K, Sasaki S : Differential dietary habits among 570 young underweight Japanese women with and without a desire for thinness : a comparison with normal weight counterparts. Asia Pacific J Clin Nutr 25 : 97-107, 2016

24. Pescatello LS, Buchner DM, Jakicic JM, Powell KE, Kraus WE, Bloodgood B, Campbell WW, Dietz S, Dipietro L, George SM, Macko RF, McTiernan A, Pate RR, Piercy KL; 2018 Physical Activity Guidelines Advisory Committee : Physical activity to prevent and treat hypertension : a systematic review. Med Sci Sports Exerc 51 : 1314-1323, 2019

25. Ofori-Asenso R, Owen AJ, Liew D : Skipping breakfast and the risk of cardiovascular disease and death : a systematic review of prospective cohort studies in primary prevention settings. J Cardiovasc Dev Dis 6 : e30, 2019. doi : $10.3390 /$ jcdd 6030030 .

26. Jardim TV, Gaziano TA, Nascente FM, Carneiro CS, Morais P, Roriz V, Mendonça KL, Póvoa TIR, Barroso WKS, Sousa ALL, Jardim PCBV : Multiple cardiovascular risk factors in adolescents from a middle-income country : prevalence and associated factors. PLoS One 13 : e0200075, 2018. doi : 10.1371/journal.pone.0200075.

27. Shah RV, Abbasi SA, Neilan TG, Hulten E, Coelho-Filho O, Hoppin A, Levitsky L, de Ferranti S, Rhodes ET, Traum A, Goodman E, Feng H, Heydari B, Harris WS, Hoefner DM, McConnell JP, Seethamraju R, Rickers C, Kwong RY, Jerosch-Herold M : Myocardial tissue remodeling in adolescent obesity. J Am Heart Assoc 2 : e000279, 2013. doi : 10.11 
61/JAHA.113.000279.

28. Alpert MA, Omran J, Bostick BP : Effects of obesity on cardiovascular hemodynamics, cardiac morphology, and ventricular function. Curr Obes Rep 5 : 424-434, 2016

29. Bhatheja S, Panchal HB, Ventura H, Paul TK: Obesity cardiomyopathy : pathophysiologic factors and nosologic reevaluation. Am J Med Sci 352 : 219-222, 2016

30. Saliba LJ, Maffett $\mathrm{S}$ : Hypertensive heart disease and obesity : a review. Heart Fail Clin 15 : 509-517, 2019
31. Jardim TV, Carneiro CS, Morais P, Roriz V, Mendonça KL, Nascente FM, Póvoa TIR, Barroso WKS, Sousa ALL, Jardim PCV : White-coat, masked and sustained hypertension detected by home blood pressure monitoring in adolescents : prevalence and associated factors. Blood Press $27: 151-157,2018$

32. Fantin F, Giani A, Zoico E, Rossi AP, Mazzali G, Zamboni $\mathrm{M}$ : Weight loss and hypertension in obese subjects. Nutrients 11 : e1667, 2019. doi : 10.3390/nu11071667. 